\title{
Continuidade e Mudança - \\ a dinâmica de uma instituição religiosa: a Igreja Católica na América Latina - Uma resenha
}

Continuity and Change - The Dynamics of a Religious Institution: The Catholic Church in Latin America - A Review

Livro/Book:

ANDES, Stephen J.C.; YOUNG, Julia. Local Church, Global Church: Catholic Activism in Latin America from Rerum Novarum to Vatican II. Washington, DC, The Catholic University of America Press, $2016 .{ }^{1}$

Nas décadas 60 a 80 do século XX, a Igreja Católica na América Latina e no Caribe estava no centro não só de Roma, mas também da imprensa local e internacional, bem como das academias. Foi o momento do desenvolvimento de um discurso teológico e de uma ação pastoral considerados inéditos: a Teologia da Libertação e as comunidades eclesiais de base, conhecidas como CEBs. O horizonte desse discurso e da prática era o da defesa dos pobres e da justiça social. O contexto

Resenha recebida em 21 de fevereiro de 2018 e aprovada em 12 de março de 2018.

\footnotetext{
* Doutora em Ciências Sociais pela École des Hautes Études en Sciences Sociales, Paris (1991). Professora da PUC São Paulo. País de origem: Brasil. E-mail: mjrosado@uol.com.br

${ }^{1}$ Resenha publicada originalmente em inglês, na Social Sciences in mission 30, ISSN: 1874-8937.

Tradução de Joaquim Pereira; revisão de Eliane Brito.
} 
das ditaduras no continente levou uma parte da Igreja a uma posição de confronto diante dos militares no poder. O adjetivo "progressista" foi ocasionalmente associado ao do clero católico, especialmente no Brasil, já que em outros países, como a Argentina, havia apoio eclesiástico para o golpe civil-militar. O ativismo dos leigos foi particularmente apoiado pela hierarquia, seja no campo religioso ou no campo sociopolítico.

Após a eleição de João Paulo II em Roma, um papa vindo da Polônia, a política pastoral mudou de direção. A afirmação de uma identidade confessional católica substituiu o ecumenismo de anos anteriores e o objetivo era o combate ao socialismo. A Teologia da Libertação foi atacada e teólogas e teólogos submetidos a penalidades. As comunidades emocionais tomaram o lugar das CEBs (BENEDETTI, 2009, p. 19) ${ }^{2}$. Mais uma vez, a Igreja muda seu curso sem se deixar ser ela mesma. As palavras do Papa Pio X não deixam dúvidas: "A Igreja em sua longa história e em todas as ocasiões mostrou com sabedoria que ela possui o maravilhoso poder de se adaptar às mudanças das condições da sociedade civil. Assim, preservando a integridade e a imutabilidade da fé e da moral e defendendo seus direitos sagrados, ela facilmente dobra-se e acomoda-se a circunstâncias essenciais e acidentais que pertencem aos vários estágios de civilização e às novas exigências da sociedade civil” (citado em ANDES; YOUNG, 2016, p. 13-14).

Este quadro rapidamente esboçado acima nos permite compreender uma dinâmica eclesiástica constante na história da Igreja Católica. Além de sua ação religiosa, é uma instituição fundamental na política global, regional e local. Adaptase de forma constante e seletiva aos contextos de acordo com os interesses institucionais e a missão espiritual 3. Essa dinâmica é realizada em uma dialética de afirmação de continuidade e de proposição de mudanças.

\footnotetext{
2 "Quando se considera os últimos quarenta anos da história da Igreja Católica (e por exceção, das igrejas cristãs em geral), os grandes sonhos e as aspirações realizadas, embora tão limitadas - o ecumenismo, a luta comum pela justiça e pela paz - foram esquecidos a favor dos interesses internos dos grupos eclesiásticos. No caso católico, os seus líderes foram absolvidos (pela instituição) ou postos em silêncio". Tradução da autora. (BENEDETTI, 2009, p. 19).

${ }^{3}$ Scott Mainwaring compreendeu este duplo caráter da instituição, ao mesmo tempo religiosa e política, e as tensões entre o cumprimento da missão e a necessidade de satisfazer os interesses mais práticos da instituição. (MAINWARING, 1986).
} 
O livro em questão - Local Church, Global Church. Catholic Activism in Latin America from Rerum Novarum to Vatican II (1890 - 1962) - insere-se nesta perspectiva analítica, tentando mostrar este jogo de adaptação e de continuidade ao trabalho no continente americano. Mesmo reconhecendo as mudanças notáveis introduzidas pelo Vaticano II, a tese é que, ao contrário do que é sugerido por uma certa literatura de historiografia e teologia latino-americana, o ativismo católico dos anos 60 e 80 teve suas origens no período anterior, tendo, em parte, como ponto de partida a encíclica Rerum Novarum. Na introdução, leia: "Na verdade, para um entendimento mais completo do contexto que formou a igreja latinoamericana contemporânea em toda a sua complexidade, devemos olhar mais para trás na história. Se fizermos isso, descobriremos que as mudanças que apareceram tiveram sua origem com o Concílio Vaticano II - foi incrementado o foco na justiça social, na organização dos leigos e no ativismo clerical - estavam realmente em andamento no final do século XIX”. (p. XV)

Os textos deste trabalho coletivo oferecem resultados de pesquisa em diversos países. É um estudo histórico detalhado que informa como a hierarquia católica mobilizou os fiéis em um ativismo religioso sem precedentes. O tópico teórico que conduz às análises é o expresso no título e bem explicado pelos organizadores: “A Igreja Católica apresenta um exemplo particularmente coeso de uma rede religiosa transnacional. Neste contexto, as igrejas nos níveis local e nacional foram ligadas ao papado através de iniciativas pastorais, mantendo uma grande autonomia a nível local. Redes religiosas transnacionais na América Latina serviram para 'ampliar, aprofundar e personalizar um sistema religioso global que fosse legítimo, poderoso e bem organizado” (p. XIV).

Apenas uma análise profunda das interconexões católicas nos níveis locais e transnacionais nos séculos XIX e início do século XX pode explicar a intensa ação desenvolvida após o Vaticano II pela Igreja na América Latina e a importância global alcançada por esta Igreja. Organizações seculares, missionários, sociedades devocionais, os estudantes foram mobilizados em grande parte e se tornaram os 
principais atores religiosos. Este é o momento em que congregações religiosas de mulheres e homens, várias expulsas de seus países de origem, vêm trabalhar no continente. $\mathrm{Na}$ introdução, podemos ler: O foco deste livro no catolicismo latinoamericano do período pré-Vaticano II já estava firmemente ligado às correntes globais antes da década de 1960. Este caráter transnacional único da Igreja Católica com sua estrutura piramidal e masculina, uma única autoridade - o Papado -, permitiu a formação de redes que atravessam a Europa e os Estados Unidos, cultura com métodos, símbolos, valores e métodos característicos.

São essas questões que atravessam os capítulos que compõem as três partes nas quais o trabalho está dividido. Centrado em diferentes assuntos - a recepção da Rerum Novarum, em geral e no Brasil, em particular; as peculiaridades religiosas no México, devido ao processo revolucionário e aos novos dados sobre os Cristeros reunidos nos arquivos secretos do Vaticano; a figura exemplar - e de exceção - de uma mulher, Sofía del Valle; Ativismo católico nos círculos acadêmicos; o movimento Antigonish do Canadá para a América Latina, a Ação Cultural Popular na Colômbia e as cooperativas maias na Guatemala - os capítulos seguem a linha de análise do livro: O catolicismo latino-americano operava em uma esfera global muito antes do Vaticano II (p. XXIX). As origens de uma forte cultura de ativismo católico nos países da região se referem a uma poderosa rede local, nacional e transnacional que foi esquecida pelos pesquisadores.

Posteriormente, algumas observações mais gerais sobre o trabalho. Primeiro, afirmar seu interesse acadêmico para todos aqueles que procuram compreender e analisar esta instituição complexa em sua ação sociopolítica e religiosa na América Latina. A obra destaca a necessidade fundamental de levar em consideração o caráter global da Igreja Católica, a fim de compreender seu sucesso na mobilização de todas as suas forças - leigos, mulheres e homens; religiosos e religiosas; clero - e atingir seus objetivos a nível local. A Igreja aparece neste período histórico como "globalizada", como romanizada, ultramontana e local graças às redes pelas quais podia operar nos Estados Unidos, no Canadá e na 
Europa, ligando-os aos grupos latino-americanos. Nesse sentido, uma entrada mais direta no jogo político em questão poderia ter esclarecido sobre como o ativismo católico foi articulado aos interesses americanos na região. Igreja e Governo dos Estados Unidos foram articulados na luta contra o comunismo. Poderíamos reconhecer nesta operação conjunta no momento o antecedente da interferência americana nos golpes militares na década de 1960, em vários países, apoiados também pela hierarquia católica, na defesa dos valores cristãos contra o "perigo vermelho".

Outra observação é a respeito do gênero. Dado que a Igreja Católica em sua estrutura organizacional exclui as mulheres porque as mulheres são a explicitação de uma misoginia histórica, a análise da organização não pode evitar as relações entre os sexos que atravessam a instituição e a constituem. Há, é verdade, algumas considerações sobre a questão, mas estão espalhadas nos capítulos e não fazem parte do quadro analítico geral do trabalho. O uso do gênero masculino invisibiliza as mulheres. Não se sabe se havia mulheres nas cooperativas, nas comunidades acadêmicas ou no movimento Antigonish.

O capítulo sobre Sofia del Valle aparece como uma exceção. E é como uma figura excepcional que é objeto de um texto específico, incorporando o ideal da feminilidade, de uma feminilidade católica.

O livro tem o raro mérito de confiar em uma vasta bibliografia entre as quais várias obras em espanhol e português. Já Grace Davie chamou a atenção para as dificuldades colocadas pelas limitações de pesquisadores europeus e americanos para o acesso à produção acadêmica que não está em inglês ou francês4. No entanto, a tese proposta de um esquecimento na historiografia atual do passado ao qual o ativismo católico após o Concílio Vaticano II seria devedor deve ser revisada

\footnotetext{
4 “O que é evidente, no entanto, é a incapacidade da maioria dos estudiosos britânicos e norte-americanos (senão todos) de acessar a literatura sociológica em qualquer outro idioma que não o seu. A questão da tradução continua a ressoar. A maioria dos estudiosos continentais pode fazer melhor, levando a um desequilíbrio notável na escrita sociológica. Muitos destes últimos, por exemplo, fazem referência à literatura de língua inglesa em seu trabalho; No entanto, o inverso raramente é o caso até que a pressão para fornecer uma edição em inglês se torne opressora". (DAVIE, 2003, p. 68).
} 
e, pelo menos, matizada. A produção da Comissão para o Estudo da História da Igreja na América Latina e no Caribe (CEHILA) e a Teologia da Libertação não podem ser julgadas por um único autor e algumas obras. Um estudo aprofundado de todas as publicações dos(as) autores(as) da Comissão, que excede cem, e da produção considerável da Teologia da Libertação, incluindo a Teologia Feminista, pode dar outra perspectiva para a análise.

Para concluir, Local Church, Global Church é um livro notável, leitura obrigatória para quem tem interesse em entender o ativismo católico na América Latina no final do século XIX e início do século XX. A riqueza dos dados empíricos que suportam as análises em cada um dos capítulos mostra a coerência e a pertinência das análises propostas. É necessário aguardar a sua tradução para o Português e para o Espanhol para que este esteja disponível para o maior número de leitores do continente que estuda.

\section{REFERÊNCIAS}

ANDES, Stephen J.C.; YOUNG, Julia. Local Church, Global Church: Catholic Activism in Latin America from Rerum Novarum to Vatican II. Washington, DC, The Catholic University of America Press, 2016

BENEDETTI, Luiz Roberto. Novos Rumos do Catolicismo. In: CARRANZA, Brenda; MARIZ, Cecília; CAMURÇA, Marcelo. Novas comunidades católicas: em busca do espaço pós-moderno. Aparecida, SP: Ideias \& Letras, 2009.

DAVIE, Grace. The evolution of the Sociology of Religion: Theme and variations. In: DILLON, Michele (Edit.). Handbook of the Sociology of Religion. Cambridge: CUP, 2003.

MAINWARING, Scott. The Catholic Church and Politics in Brazil: 1916-1985. California: Stanford University Press, 1986. 